\title{
Gray matter microglial activation in relapsing vs progressive MS
}

\author{
A [F-18]PBR06-PET study
}

Tarun Singhal, MD, Kelsey O'Connor, BS, Shipra Dubey, PhD, Hong Pan, PhD, Renxin Chu, PhD, Shelley Hurwitz, PhD, Steven Cicero, BS, Shahamat Tauhid, MD, David Silbersweig, MD, Emily Stern, MD, Marie Kijewski, DSc, Marcelo DiCarli, MD, Howard L. Weiner, MD, and Rohit Bakshi, MD, MA

\author{
Correspondence \\ Dr. Singhal \\ tsinghal@bwh.harvard.edu
}

Neurol Neuroimmunol Neuroinflamm 2019;6:e587. doi:10.1212/NXI.0000000000000587

\section{Abstract}

\section{Objective}

To determine the value of [F-18]PBR06-PET for assessment of microglial activation in the cerebral gray matter in patients with MS.

\section{Methods}

Twelve patients with MS (7 relapsing-remitting and 5 secondary progressive [SP]) and 5 healthy controls (HCs) had standardized uptake value (SUV) PET maps coregistered to 3T MRI and segmented into cortical and subcortical gray matter regions. SUV ratios (SUVRs) were global brain normalized. Voxel-by-voxel analysis was performed using statistical parametric mapping (SPM). Normalized brain parenchymal volumes (BPVs) were determined from MRI using SIENAX.

\section{Results}

Cortical SUVRs were higher in the hippocampus, amygdala, midcingulate, posterior cingulate, and rolandic operculum and lower in the medial-superior frontal gyrus and cuneus in the MS vs HC group (all $p<0.05)$. Subcortical gray matter SUVR was higher in SPMS vs RRMS $(+10.8 \%$, $p=0.002)$ and $\mathrm{HC}(+11.3 \%, p=0.055)$ groups. In the MS group, subcortical gray matter SUVR correlated with the Expanded Disability Status Scale (EDSS) score $(\mathrm{r}=0.75, p=0.005)$ and timed 25-foot walk (T25FW) $(\mathrm{r}=0.70, p=0.01)$. Thalamic SUVRs increased with increasing EDSS scores $(r=0.83, p=0.0008)$ and T25FW $(r=0.65, p=0.02)$ and with decreasing BPV $(\mathrm{r}=-0.63, p=0.03)$. Putaminal SUVRs increased with increasing EDSS scores $(0.71, p=$ $0.009)$ and with decreasing BPV $(r=-0.67, p=0.01)$. On SPM analysis, peak correlations of thalamic voxels with BPV were seen in the pulvinar and with the EDSS score and T25FW in the dorsomedial thalamic nuclei.

\section{Conclusions}

This study suggests that [F-18]PBR06-PET detects widespread abnormal microglial activation in the cerebral gray matter in MS. Increased translocator protein binding in subcortical gray matter regions is associated with brain atrophy and may link to progressive MS. 


\section{Glossary}

AAL = automated anatomic labeling; $\mathbf{B P V}=$ brain parenchymal volume; $\mathbf{C}-\mathrm{SUVR}=$ total cortical gray standardized uptake value ratio; EDSS = Expanded Disability Status Scale; HC = healthy control; $\mathbf{R C P}$ = radiochemical purity; ROI = region of interest; $\mathbf{R R}=$ relapsing-remitting; $\mathbf{S C}-\mathbf{S} \mathbf{V R}=$ total subcortical gray matter standardized uptake value ratio; $\mathbf{S P}$ = secondary progressive; SUVR = standardized uptake value ratio; T25FW $=$ timed 25 -foot walk; TSPO $=$ translocator protein.

There has been increasing recognition of gray matter pathology in MS since the seminal histopathologic description of gray matter plaques by Brownell et al. in 1962. ${ }^{1,2}$ Microglial activation and neuronal loss have been demonstrated in gray matter MS lesions and normal-appearing gray matter. ${ }^{1}$ Brain atrophy has been associated with disease progression, ${ }^{3}$ and regional gray matter loss has been associated with specific clinical impairment. ${ }^{4}$ However, the mechanism of brain atrophy in MS is not clear. There is a need to better understand the role of gray matter microglial activation in disease pathogenesis.

[F-18]PBR06 [N-(2,5-dimethoxybenzyl)-2-(18)F-fluoro-N(2-phenoxyphenyl)acetamide] is a second-generation PET radioligand, targeting the $18 \mathrm{kDa}$-translocator protein (TSPO), which is overexpressed on activated microglia/ macrophages. ${ }^{5}$ The longer physical half-life of F-18 (110 minutes) as compared to C-11 (20 minutes, used to label conventional TSPO ligands such as [C-11]PK11195) enables improved image quality, increased signal-to-noise ratio, and higher clinical feasibility. ${ }^{6}$ Strong correlations of [F-18] PBR06-binding with both CD68 expression and TSPOantibody reactivity have been demonstrated in multiple disease models. ${ }^{7,8}$ [F-18]PBR06 has been studied in healthy human volunteers but not in MS, except for our recent study on white matter microglial activation in MS. ${ }^{9}$ The aims of this pilot study were to assess differences in microglial activity in the cortical and subcortical gray matter regions between patients with MS and healthy controls ( $\mathrm{HCs}$ ), and between patients with relapsing-remitting (RR) and secondary progressive (SP) MS, and to identify any association of microglial activation with brain atrophy and physical disability using [F-18]PBR06 PET.

\section{Methods}

\section{Participants}

Eighteen MS and 7 HC participants were initially enrolled. Two MS and $2 \mathrm{HC}$ participants were low-affinity binders and were excluded from the study (see the Genotyping section below). Four additional MS participants subsequently lost interest or were lost to follow-up after initial screening. Ultimately, 12 patients with MS (7 RR and 5 SP; 8 women [67\%]) and $5 \mathrm{HC}$ participants (3 women, 60\%) completed the study. Participant characteristics are summarized in table 1 and detailed for each participant in table 2 .

Clinical course (RR or SP) was initially determined by the treating neurologists and documented in the patient's chart.
The clinical course was subsequently verified by TS by chart review, and determination of SPMS was based on the 2013 International Advisory Committee on Clinical Trials of MS criteria. $^{10}$ The inclusion criteria required patients with SP to have demonstrated an increase in the Expanded Disability Status Scale (EDSS) score by 1.0 or 0.5 , if the baseline EDSS score was $<5$ or $\geq 5.5$, respectively, in the last 1 year. Patients with RR were included if there was a history of a clinical relapse in the last 1 year or if there was evidence of a new or enlarging T2 bright lesion on MRI or a gadolinium-enhancing lesion on T1-weighted MRI. Patients were excluded if they received corticosteroids in the last 1 month before PET scanning. The median time interval between formal clinical assessment and PET scanning was 5.1 (range 1.1-25.6) weeks. There was no history of relapses or clinical deterioration between the clinical visits immediately before and after the PET scanning.

\section{Standard protocol approvals, registrations, and patient consents}

The study is registered on clinicaltrials.gov with the clinical trial identifier number, NCT02649985. The study was approved by the Institutional Review Board and Radioactive Drug Research Committee at Brigham and Women's Hospital; written informed consent was obtained from all participants.

\section{Genotyping}

Blood samples drawn on the initial screening visit were genotyped for DNA polymorphism of the TSPO gene on chromosome 22q13.2, using a TaqMan assay. High-affinity and medium-affinity binders were included in the study, whereas low-affinity binders (4 participants, including 2 MS and 2 HC) were excluded. Among the 12 included patients with MS, 7 (58\%) were high-affinity and 5 were medium-affinity binders, and among the HCs, 2 (40\%) were high-affinity and 3 were medium-affinity binders (table 2). There were no statistically significant differences in the TSPO-binding affinity distribution between the 2 groups (table 1).

\section{Production of radiopharmaceuticals}

[F-18]PBR06 was produced in the Nuclear Medicine/ Biomedical Imaging Research Core facility at our hospital according to standardized procedures. The product was purified by high-pressure liquid chromatography and sterilized by a $0.22-\mu \mathrm{m}$ membrane filter. The final product was dispensed in an isotonic solution that was sterile and pyrogenfree for IV administration. The radiochemical purity (RCP) of radiopharmaceuticals was determined using high-pressure 
Table 1 Participant characteristics: summary

\begin{tabular}{llll}
\hline & MS $(\mathbf{N}=\mathbf{1 2})$ & HC $(\mathbf{N}=\mathbf{5})$ & p Value \\
\hline Age (y) & $42 \pm 11.7$ & $37.8 \pm 13.3$ & 0.60 \\
\hline Sex distribution & $7 \mathrm{~F}, 5 \mathrm{M}$ & $3 \mathrm{~F}, 2 \mathrm{M}$ & 0.95 \\
\hline $\begin{array}{l}\text { TSPO-binding } \\
\text { affinity }\end{array}$ & 7 high, 5 medium & 2 high, 3 medium & 0.49 \\
\hline $\begin{array}{l}\text { Median EDSS } \\
\text { score }\end{array}$ & 3.5 & & \\
\hline \begin{tabular}{l} 
T25FW (s) \\
\hline
\end{tabular} & $7.2 \pm 3.7$ & & \\
\hline
\end{tabular}

Abbreviations: EDSS = Expanded Disability Status Scale; $\mathrm{HC}=$ healthy control; T25FW = timed 25-foot walk; TSPO = translocator protein

Data are mean $\pm S D$, unless otherwise indicated.

liquid chromatography. The organic solvents were determined using gas chromatography. The RCP of the radiopharmaceuticals was $>95 \%$.

\section{MRI acquisition and analysis}

All participants underwent MRI on the same scanner (Siemens 3T Skyra, Erlangen, Germany) using the same high-resolution acquisition protocol as previously described. ${ }^{11-13}$ This included a 2D T1-weighted spin-echo axial series (the repetition time $=$
$611-943 \mathrm{~ms}$, and echo time $=7.9 \mathrm{~ms}$, voxel size $=0.43 \times 0.43 \times$ $3 \mathrm{~mm}$ ) and a 3D magnetization-prepared rapid gradient-echo series (voxel size $1 \mathrm{~mm}^{3}$ ). The latter images were applied to a fully automated algorithm to derive normalized whole brain parenchymal volume (BPV) (SIENAX, v. 5.0; Analysis Group, fsl.fmrib.ox.ac.uk), using our previously described method. ${ }^{14}$

\section{PET acquisition and analysis}

[F-18]PBR06 was injected as a bolus injection for PET scanning using an IV catheter into the radial antecubital or other arm or hand vein; images were acquired in a list mode acquisition mode using a high-resolution PET/CT scanner (GE Discovery ECAT, Waukesha, WI).

For each participant, using the PNEURO 3.8 platform (PMOD Technologies, Zurich, Switzerland; pmod.com), summed [F-18]PBR06 PET images obtained between 60 and 90 minutes after tracer injection were coregistered to MRI, and segmentation of images into brain regions was based on the automated anatomical labeling $(\mathrm{AAL})$ template within the PNEURO utilities suite. ${ }^{15}$ Two regions of interest (ROIs) were derived after collapsing the supratentorial AAL template output: (1) a supratentorial cortical region of interest representing the union of 41 regions in each hemisphere, including the amygdala; (2) a subcortical gray matter ROI representing the union of the thalamus, caudate, putamen, and globus

Table 2 Participant characteristics: detailed

\begin{tabular}{|c|c|c|c|c|c|c|c|c|}
\hline Participant number & Sex & Age (y) & TSPO-binding affinity & Group & Disease duration (y) & Current DMT & EDSS score & T25FW (s) \\
\hline 1 & $\mathrm{~F}$ & 37 & High & $\mathrm{RR}$ & 5.2 & Fingolimod & 4 & 6.1 \\
\hline 2 & $\mathrm{M}$ & 37 & High & $\mathrm{RR}$ & 19.6 & Rituximab & 3 & 5.8 \\
\hline 3 & $\mathrm{~F}$ & 34 & Medium & $\mathrm{RR}$ & 4.8 & Fingolimod & 1 & 3.4 \\
\hline 4 & $\mathrm{M}$ & 32 & Medium & $\mathrm{RR}$ & 11.9 & Fingolimod & 1 & 4 \\
\hline 5 & $\mathrm{~F}$ & 23 & High & $\mathrm{RR}$ & 8.2 & Natalizumab & 1.5 & 4.8 \\
\hline 6 & $\mathrm{~F}$ & 41 & High & $\mathrm{RR}$ & 9.6 & Fingolimod & 1.5 & 5.0 \\
\hline 7 & $\mathrm{~F}$ & 27 & Medium & $\mathrm{RR}$ & 3.5 & Fingolimod & 2 & 4.8 \\
\hline 8 & $\mathrm{M}$ & 52 & Medium & $\mathrm{SP}$ & 14.9 & Rituximab & 6.5 & 8.5 \\
\hline 9 & $\mathrm{M}$ & 53 & High & $\mathrm{SP}$ & 19 & Rituximab & 6 & 8.5 \\
\hline 10 & $\mathrm{~F}$ & 59 & Medium & SP & 19 & Glatiramer acetate & 6 & 12.1 \\
\hline 11 & $\mathrm{~F}$ & 59 & High & $\mathrm{SP}$ & 19 & None & 6.5 & 17.1 \\
\hline 12 & $\mathrm{~F}$ & 50 & High & $\mathrm{SP}$ & 17 & Rituximab & 4.5 & 6.8 \\
\hline 13 & $M$ & 25 & Medium & $\mathrm{HC}$ & & & & \\
\hline 14 & $\mathrm{~F}$ & 45 & High & $\mathrm{HC}$ & & & & \\
\hline 15 & $\mathrm{M}$ & 60 & Medium & $\mathrm{HC}$ & & & & \\
\hline 16 & $\mathrm{~F}$ & 25 & High & $\mathrm{HC}$ & & & & \\
\hline 17 & $\mathrm{~F}$ & 34 & Medium & $\mathrm{HC}$ & & & & \\
\hline
\end{tabular}

Abbreviations: Disease duration is time from the onset of first symptoms; DMT = disease-modifying treatment; EDSS = Expanded Disability Status Scale; RR = relapsing-remitting; $\mathrm{SP}=$ secondary progressive; TSPO = translocator protein; T25FW = timed 25-foot walk. 
pallidus. To account for interparticipant differences, a total cortical gray matter and a total subcortical gray matter standardized uptake value ratio (SUVR) (C-SUVR and SCSUVR, respectively) were calculated for each participant based on normalization of the individual region's $\mathrm{SUV}_{60-90}$ to the global brain $\mathrm{SUV}_{60-90}$. To assess the appropriateness of using global $\mathrm{SUV}_{60-90}$ as a reference for normalization, global SUV $_{60-90}$ was compared between the MS and $\mathrm{HC}$ groups and showed no significant difference $(0.87 \pm 0.20$ vs $0.73 \pm 0.13, p$ $=0.22$ ). SUVRs for individual supratentorial AAL template ROIs (averages of right and left) were also obtained and assessed for group comparisons (a complete list of ROIs obtained is shown in table 1, links.lww.com/NXI/A123). Because the subcortical gray matter showed significant correlations with disability, the correlations of PET uptake in subregions within this ROI (thalamus, caudate, putamen, and globus pallidus) were further investigated. To gain additional insight into the topographic relevance of subcortical gray matter changes, a second set of post hoc analyses was performed. [F-18]PBR06 PET SUV images were processed using SPM12 software (the Wellcome Institute of Cognitive Neurology, London, UK; fil.ion.ucl.ac.uk/spm/software/). ${ }^{16}$ Stereotactic normalization of PET images to the Montreal Neurologic Institute version of Talairach space was performed. Voxel-by-voxel whole-brain multiple linear regression modeling was applied to individual scans. ${ }^{6}$ Contrast-effect images were then progressed into group-level models. Parametric images were generated to demonstrate the age- and sex-adjusted correlations of thalamic PET uptake with the EDSS score, timed 25-foot walk (T25FW), and BPV in the MS group. All image analyses were performed blinded to study group and clinical scores.

\section{Statistical analysis}

For the primary analysis, the exact Wilcoxon-Mann-Whitney test was used to assess the statistical significance of mean differences in SUVRs. For age-adjusted comparisons between SPMS vs RRMS and HC groups, analysis of covariance was used to compare groups while including age in the model. To assess associations, Spearman correlation coefficient r's were calculated. This pilot study was exploratory in nature with a small sample size that is not based on formal sample size calculations, and results should be considered hypothesis generating. Therefore, no correction was made for multiple statistical tests.

\section{Data availability}

Any unpublished study data will be available for sharing with any qualified investigators after due anonymization.

\section{Results}

\section{Group comparisons in the cortical and subcortical gray matter: MS vs HC}

There was no significant difference between MS and HC groups in the total cortical $(1.09 \pm 0.04$ vs $1.11 \pm 0.07$, $p=0.72)$ and subcortical gray matter regions $(0.93 \pm 0.06$ vs $0.88 \pm 0.06, p=0.23$ ) (figure $1, \mathrm{~A}$ and $\mathrm{B}$ ). However, the following cortical subregions showed increased SUVRs in MS vs $\mathrm{HC}$ groups (figure 1C): the rolandic operculum (1.031 \pm 0.119 vs $0.856 \pm 0.053$, mean $+20.4 \%, p=0.006)$, midcingulate $(1.131 \pm 0.097$ vs $1.013 \pm 0.049,+11.6 \%, p=0.01)$, posterior cingulate ( $1.106 \pm 0.158$ vs $0.961 \pm 0.074,+15.1 \%, p=0.03)$, hippocampus $(1.020 \pm 0.106$ vs $0.880 \pm 0.096,+15.9 \%, p=$ $0.03)$, and amygdala ( $1.037 \pm 0.075$ vs $0.898 \pm 0.125,+15.5 \%$, $p=0.01)$. On the other hand, decreased SUVRs were seen in the MS vs HC (figure 1D) in the cuneus $(1.128 \pm 0.108$ vs $1.370 \pm 0.105,-17.7 \%, p=0.001)$ and medial-superior frontal gyrus $(1.086 \pm 0.103$ vs $1.291 \pm 0.178,-15.9 \%, p=0.048)$. No other supratentorial regions from the AAL template showed a significant difference between MS and HC groups.

\section{Group comparisons in the cortical and subcortical gray matter between SPMS, RRMS, and HC groups}

On univariate analysis, total subcortical gray matter SUVR (SC-SUVR) was higher in the SPMS vs RRMS (0.988 \pm 0.029 vs $0.891 \pm 0.053,+10.8 \%, p=0.002$ ). The effect sizes and ageadjusted $p$ values for SPMS vs RRMS were 2.07 and 0.03 and those for SPMS vs HC were 1.87 and 0.10 , respectively (figure $1 \mathrm{E})$. On the other hand, total cortical SUVR was not significantly different among the SPMS, RRMS, and HC groups (figure $1 \mathrm{~F}$ ).

\section{Age-adjusted group comparisons in subregions of the subcortical gray matter between SPMS, RRMS, and HC groups}

In terms of subregions of the subcortical gray matter, thalamic SUVRs were higher in SPMS vs RRMS ( $1.250 \pm 0.018$ vs 1.099 $\pm 0.084,+13.7 \%, p=0.03)$ and SPMS vs HC $(1.250 \pm 0.018$ vs $1.087 \pm 0.060,+15.0 \%, p=0.003$ ) (figure $1 G$ ). Putaminal SUVR was $0.974 \pm 0.015$ vs $0.892 \pm 0.052$ in SP vs HC groups $(+9.2 \%)$ but did not attain statistical significance $(p=0.06)$.

\section{Age-adjusted group comparisons in subregions of the cortical gray matter between SPMS, RRMS, and HC groups}

In terms of subregions of the cortical gray matter, increased SUVRs in the SPMS vs HC group were seen in the rolandic operculum $(1.053 \pm 0.087$ vs $0.856 \pm 0.053,+23.0 \%, p=$ $0.008)$, hippocampus ( $1.068 \pm 0.093$ vs $0.88 \pm 0.096,+21.3 \%$, $p=0.04)$, midcingulate $(1.132 \pm 0.048$ vs $1.013 \pm 0.049$, $+11.7 \%, p=0.002)$, parahippocampus $(0.976 \pm 0.048$ vs 0.854 $\pm 0.049,+14.3 \%, p=0.02)$, olfactory cortex $(1.035 \pm 0.197 \mathrm{vs}$ $0.795 \pm 0.404,+30.2 \%, p=0.01)$, insula $(1.068 \pm 0.096$ vs 0.95 $\pm 0.063,+12.4 \%, p=0.04)$, and middle temporal gyrus ( $1.15 \pm$ 0.035 vs $1.131 \pm 0.07,+1.7 \%, p=0.04)$ On the other hand, decreased SUVRs in SPMS vs HC groups were seen in the dorsolateral superior frontal gyrus $(1.057 \pm 0.116$ vs $1.303 \pm$ $0.23,-18.8 \%, p=0.01)$, middle frontal gyrus $(1.133 \pm 0.062$ vs $1.25 \pm 0.077,-9.4 \%, p=0.047)$, and supplementary motor area $(1.057 \pm 0.161$ vs $1.474 \pm 0.49,-28.2 \%, p=0.02)$ Comparison of the RRMS and HC groups revealed increased 

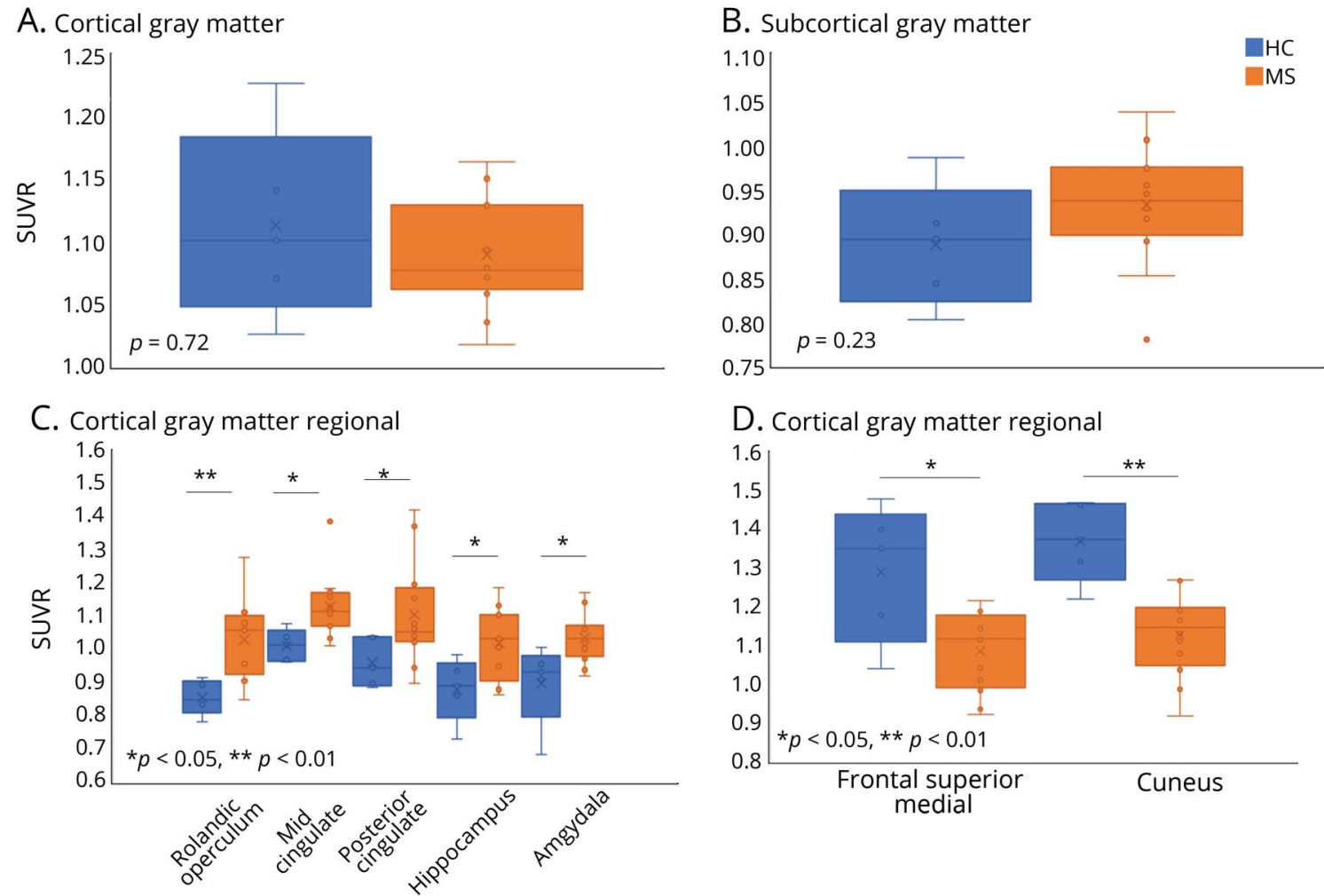

E. Subcortical gray matter

F. Cortical gray matter
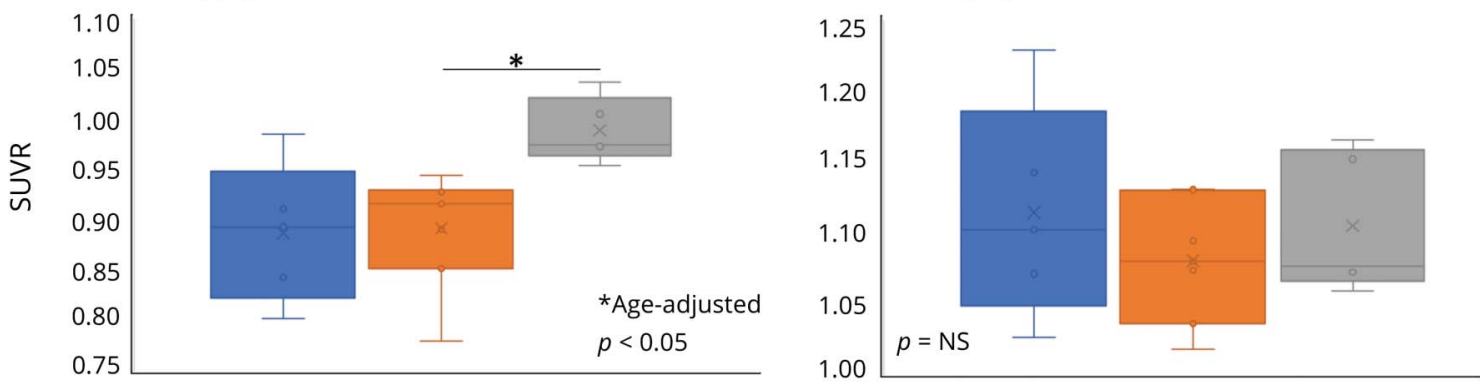

G. Subcortical gray matter nuclei

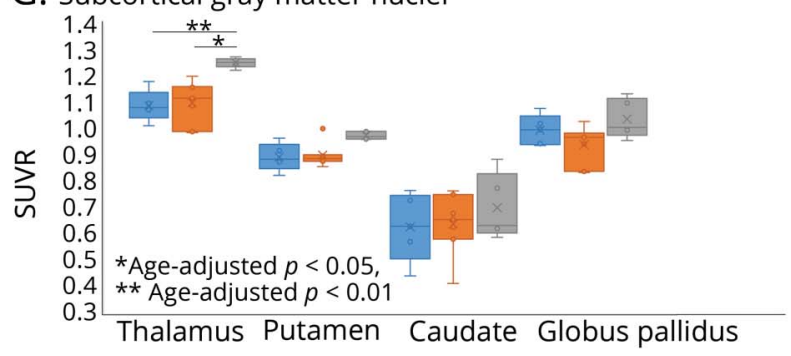

HC

RRMS

SPMS

Differences in (A and B) overall cortical and subcortical gray matter ROls between MS vs HC, (C and D) cortical subregions between MS vs HC, (E and F) overall subcortical and cortical gray matter ROIs among SPMS, RRMS, and HC groups, (G) subcortical subregions (thalamus, putamen, caudate, and globus pallidus) among SPMS, RRMS, and HC groups. Open circles in the box plots indicate individual participants, " $x$ " represents mean, horizontal line within box represents median, ends of whiskers represent minimum and maximum values, and closed circle represents outliers. $\mathrm{HC}=$ healthy control; ROI = region of interest; RR = relapsing-remitting; SP = secondary progressive; SUVR = standardized uptake value ratio.

SUVRs in the rolandic operculum $(1.014 \pm 0.142$ vs $0.856 \pm$ $0.053,+18.458 \%, p=0.03)$ and decreased SUVRs in the cuneus $(1.143 \pm 0.078$ vs $1.37 \pm 0.105,-16.569 \%, p=0.005)$. The supramarginal gyrus showed increased SUVRs $(1.247 \pm$
0.043 vs $1.177 \pm 0.085,+6 \%, p=0.007)$ in the SPMS vs RRMS group. The effect sizes for the complete list of subgroup comparisons for the cortical and subcortical subregions are provided in table 2, links.lww.com/NXI/A123. 


\section{Relationship between PET and physical disability}

In the MS group, there were significant correlations between the EDSS score and subcortical gray matter SUVR $(\mathrm{r}=0.74, p$ $=0.005)$ (figure 2A) but not cortical SUVR $(\mathrm{r}=0.05, p=0.87)$. There were significant correlations between the EDSS score and SUVR in the thalamus $(\mathrm{r}=0.83, p=0.0008)$ and putamen $(\mathrm{r}=0.71, p=0.0089$ ) (figures $2 \mathrm{~B}$ and $3 \mathrm{~A})$. No significant correlations were seen between the EDSS score and SUVR in the caudate $(\mathrm{r}=0.28, p=0.37)$ or globus pallidus $(\mathrm{r}=0.42, p=$ $0.17)$. On SPM analysis, age- and sex-adjusted correlations were seen in the thalamus between the EDSS score and PET uptake $(p=0.02)$. The peak thalamic voxels showing significant correlation with the EDSS score in the thalamus were localized to the dorsomedial nucleus (figure 3B).

\section{Relationship between PET and T25FW}

In the MS group, there were significant correlations between T25FW and subcortical gray matter SUVRs $(\mathrm{r}=0.70, p=0.01)$ (figure 2C) but not cortical SUVR. There was a significant correlation between T25FW and SUVR in the thalamus $(\mathrm{r}=$ $0.65, p=0.02$ ) (figures $2 \mathrm{D}$ and $3 \mathrm{~A}$ ). The correlation coefficient between T25FW and putaminal SUVR was 0.57 but did not attain statistical significance $(p=0.053)$ (figure 2D). No significant correlations were seen between T25FW and SUVR in the caudate $(\mathrm{r}=0.44, p=0.15)$ and globus pallidus $(\mathrm{r}=0.40, p$ $=0.19$ ). On SPM analysis, age- and sex-adjusted correlations were seen in the thalamus between T25FW and PET uptake ( $p$ $=0.02$ ). The peak thalamic voxels showing significant correlation with $\mathrm{T} 25 \mathrm{FW}$ in the thalamus were localized to the dorsomedial nucleus (figure 3C).

Figure 2 Correlations of subcortical gray matter SUVRs with the EDSS score, T25FW, and BPV in MS

A

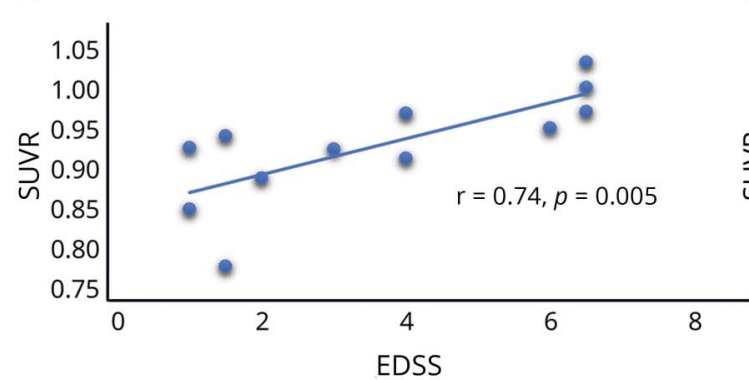

B

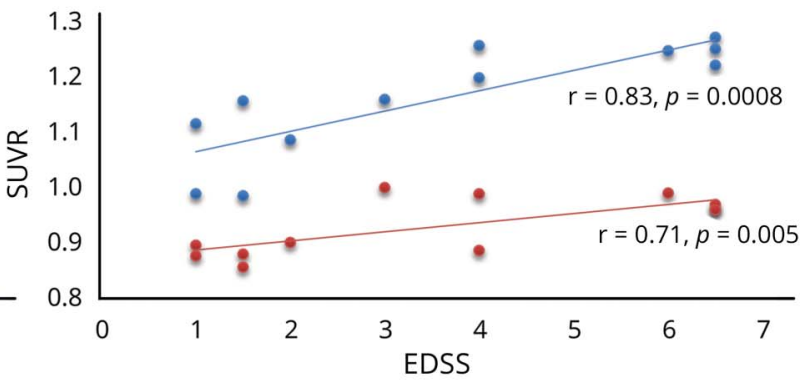

C

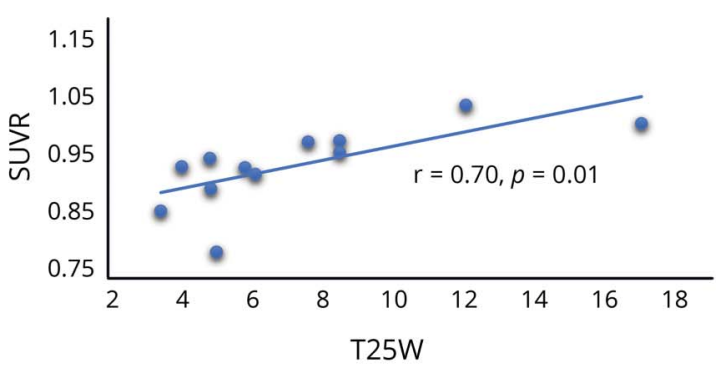

D

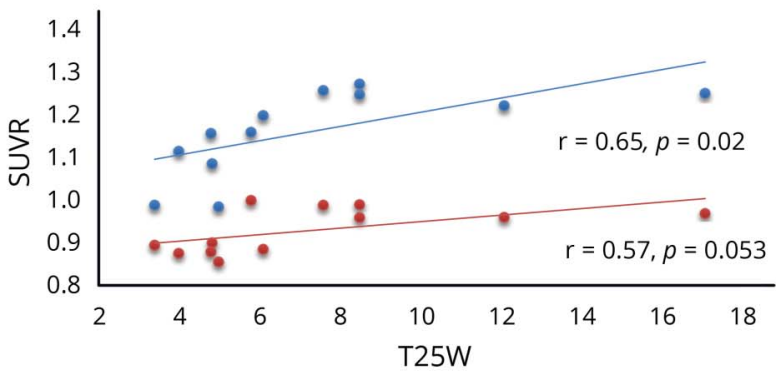

E

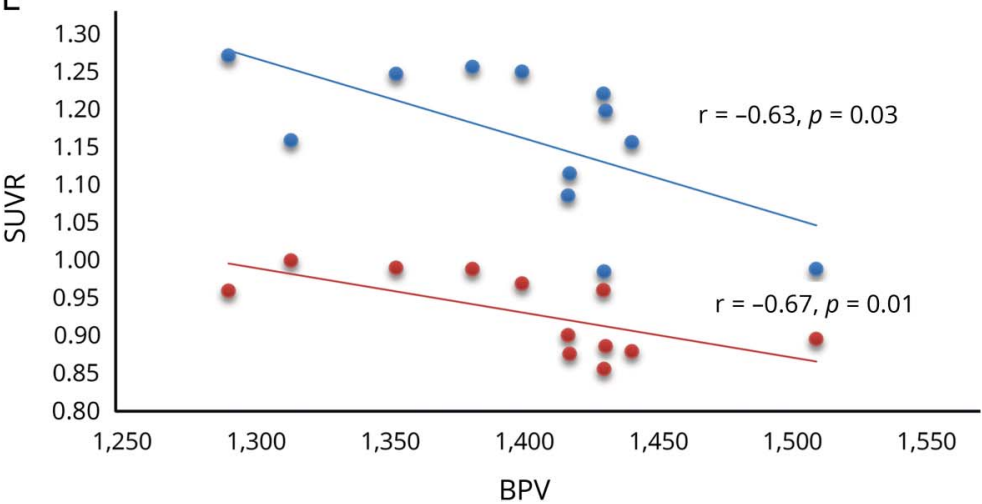

Correlations in the MS group of (A) subcortical gray matter SUVR vs EDSS score, (B) thalamic and putaminal SUVR vs EDSS score, (C) subcortical gray matter SUVR vs T25FW, (D) thalamic and putaminal SUVR vs T25FW, and (E) thalamic and putaminal SUVR vs BPV. In panels (A) and (C), blue dots represent subcortical gray matter values. In panels (B), (D), and (E), blue dots represent thalamic values and red dots represent putaminal values. BPV = normalized brain parenchymal volume; EDSS = Expanded Disability Status Scale; SUVR = standardized uptake value ratio; T25FW = timed 25-foot walk. 

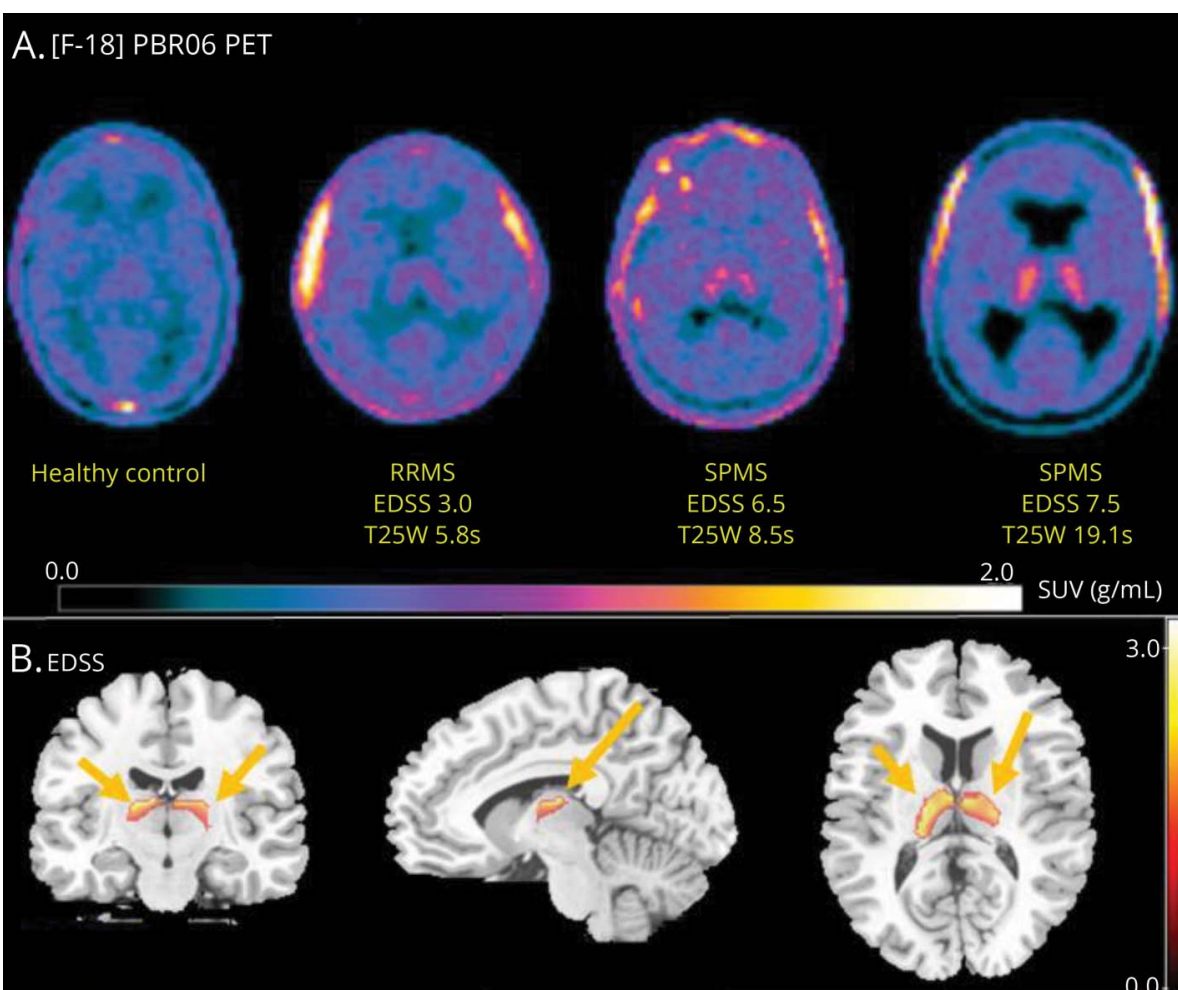

3.0
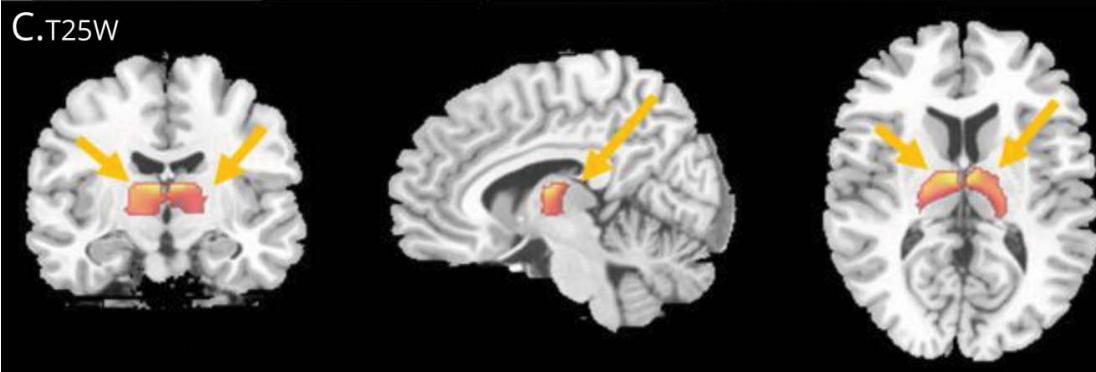

0.0

D. BPV

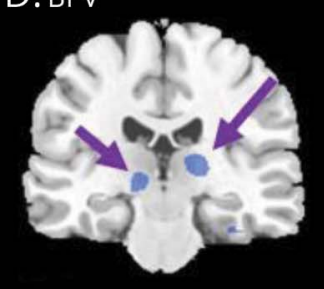

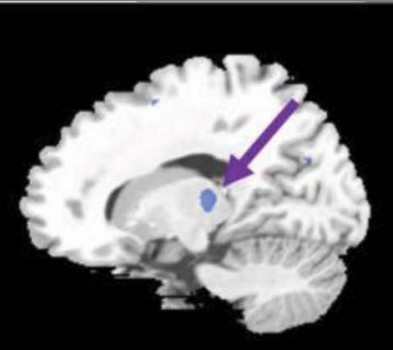

(A) [F-18]PBR06 PET sample images of an individual healthy control and patients with RRMS or SPMS. (A) SUV images were summed from 60 to 90 minutes after radiotracer injection. Images showing higher thalamic uptake with higher disability (SUVRs 1.08, $1.16,1.24$, and 1.4 , respectively). All participants are age-matched, high-affinity binders. (B-D) Age- and sex-adjusted SPM analysis showing correlations in the MS group of PET uptake with the EDSS score T25FW, and BPV in the thalamus. The color bars represent T-scores, and the colored highlights show the localization of peak clusters of voxels, demonstrating increases with the EDSS score and T25FW in the dorsomedial nucleus of the thalamus (orange arrows) and a decrease with BPV in the pulvinar (purple arrows). BPV = normalized brain parenchymal volume; EDSS = Expanded Disability Status Scale; HC = healthy control; RR = relapsing-remitting; $\mathrm{SP}=$ secondary progressive; SUVR = standardized uptake value ratios; T25FW = timed 25 -foot walk.

\section{Relationship between PET and whole- brain volume}

There was no significant correlation between overall cortical and subcortical gray matter SUVRs and BPV $(\mathrm{r}=0.31, p=0.32$ and $\mathrm{r}=0.38, p=0.22$, respectively). However, correlation analysis revealed a relationship between decreasing BPV and increasing SUVRs in the thalamus $(\mathrm{r}=-0.63, p=0.03)$ and putamen $(\mathrm{r}=-0.67, p=0.01)$ (figure $2 \mathrm{E}$ ). No significant correlations were seen between BPV and SUVR in the caudate $(\mathrm{r}=0.21, p=0.51)$ and globus pallidus $(\mathrm{r}=-0.29, p=0.36)$.
On SPM analysis, peak thalamic voxels showing significant ageand sex-adjusted decreases in BPV with increasing PET uptake were localized to the pulvinar $(p=0.02)$ (figure 3D).

\section{Discussion}

The key findings of our pilot study are as follows: (1) Subcortical gray matter demonstrated higher microglial activation in patients with SPMS compared with patients with RRMS 
and HCs, and this activation correlated with physical disability measures (EDSS score and T25FW) in patients with MS; (2) Thalamic and putaminal microglial activation primarily drove these findings in the subcortical gray matter, and thalamic microglial activation correlated with brain atrophy; (3) Regional cortical microglial activation in several limbic and paralimbic cortical regions (but not total cortical gray matter microglial activation) was increased in the MS group.

These PET findings underscore the role of microglial activation in progression of disease in MS with accumulation of microglial activation burden in SPMS, particularly in the subcortical gray matter. Gray matter microglial activation in MS has not been studied before using [F-18]PBR06, a longerhalf-life PET tracer. There is an urgent need to identify an imaging biomarker linked to progressive MS, and our results suggest that [F-18]PBR06 PET is a promising technique in this regard. Increased microglial activation in SPMS has been previously reported using [C-11]PK11195 in the cortical gray matter ${ }^{17}$ and using [C-11]PBR28 in cortical and subcortical gray matter regions, ${ }^{18}$ but both [C-11]PK11195 and [C-11] PBR28 are short half-life PET tracers, which are not easily adapted for routine clinical use.

Our study demonstrates the correlation of thalamic microglial activation with brain atrophy, EDSS score, and T25FW suggesting a central role of thalamic neuroinflammation in the pathogenesis and disease progression in MS. Extensive pathologic changes have been demonstrated in the thalamus ${ }^{19}$ that may also be related to the high thalamic iron content. ${ }^{20}$ Thalamic elevation of myoinositol concentration, reflecting increased glial activity, has been reported in MS using magnetic resonance spectroscopy. ${ }^{21}$ Thalamic atrophy is known to occur throughout the course of MS at an accelerated rate, compared with $\mathrm{HCs},{ }^{22}$ and microglial activation may play a causative role in its development. This aspect is a key to understanding of the mechanism of brain atrophy in MS and requires further investigation. A previous PET study has demonstrated an association of cortical thinning with thalamic TSPO binding, using a C-11 labeled tracer. ${ }^{18}$ Progressive reductions in thalamic and putaminal T2-hypointensity, suggesting increasing iron deposition, have been associated with clinical progression in a 4-year longitudinal study of patients with MS. ${ }^{23}$ Increased thalamic TSPO binding in patients with SPMS $^{24}$ and in a separate cohort of 8 patients with RRMS, 3 with PPMS, and 1 with SPMS ${ }^{25}$ compared with HCs has been described using [C-11]PK11195. ${ }^{24,25}$ Similarly, several subcortical gray matter regions, including the thalamus and putamen, demonstrated demyelination, microglial activation, and neurodegeneration on pathologic examination of brain sections from patients with MS compared with controls. ${ }^{19}$ We found correlation of microglial activation in the dorsomedial thalamic nucleus with increasing disability and correlation of brain atrophy with microglial activation in the pulvinar. These findings are similar to a recent report of decreased magnetic susceptibility in the pulvinar in SPMS and in the rest of thalamus including the dorsomedial nucleus in patients with RRMS. ${ }^{26}$
Chronic microglial activation may lead to cellular injury and iron depletion from oligodendrocytes, accounting for PET findings and decreased magnetic susceptibility in these regions. $^{26}$

Cortical gray matter findings of our study are consistent with pathologic and neuroimaging data available in the literature. Extensive hippocampal demyelination accompanied by microglial activation has been demonstrated on autopsy examination of MS brains. ${ }^{27}$ Several of these specimens demonstrated involvement of both the hippocampus and parahippocampal cortices. ${ }^{27,28}$ Hippocampal elevation of myoinositol concentration, reflecting increased glial activity, has been reported in MS using magnetic resonance spectroscopy. ${ }^{21}$ Of interest, in an autopsy study of patients with SPMS, ectopic B-cell follicles were most frequently found in forebrain regions, including the temporal and cingulate cortex, and correlated with increased demyelination and parenchymal $\mathrm{CD} 68^{+}$cells in proximity to these regions. ${ }^{29}$ Regional brain atrophy patterns have been identified, and atrophy in temporal and cingulate cortical regions has been associated with cognitive changes in MS. ${ }^{30}$ Other PET studies using C-11-labeled radioligands have shown similar results on cross-sectional comparison. Using [C-11]PK11195, spatially heterogeneous increases in TSPO binding were demonstrated in multiple cortical brain regions, including the parahippocampal and fusiform gyri. ${ }^{17}$ Another PET study demonstrated increased hippocampal TSPO binding in MS vs HCs that correlated with depression scores and hippocampal functional connectivity measures. ${ }^{31}$

Of interest, the cuneus and medial-superior frontal gyrus showed reduced PET uptake in patients with MS in our study. This finding may represent a partial volume effect from severe atrophy in these regions or locally "burnt out" disease with chronic scar formation and requires further confirmation and evaluation in future studies.

The underlying mechanisms connecting cortical and subcortical microglial activation in MS are not clear. The relationship between cortical and thalamic pathology may be mediated via thalamocortical projection pathways. It is known that the "core" or C-type thalamic cells project to layer 4 of the cerebral cortex and "matrix" or M-type thalamic neurons project to the apical dendritic tufts in outermost cortical layer 1 , which, in turn, is affected by the subpial gray matter lesions that are a specific aspect of MS pathology. ${ }^{32}$ In addition, diffusion tensor fractional anisotropy values have been reported to be reduced in the cingulum, fornix, and uncinate fasciculus, along with thalamic and hippocampal atrophy, suggesting disruption of hippocampal-thalamic-prefrontal connections in patients with RRMS. ${ }^{33}$

Microglial activation may be a cause or effect of neurodegeneration, ${ }^{34}$ and the cross-sectional nature of our study cannot definitively answer that question. Mechanistically, activated microglia can cause ongoing injury in non-antigen- 
dependent manner, mediated via the production of cytokines, glutamate, oxygen radicals, nitric oxide, matrix proteases, and putative proapoptotic signals. ${ }^{35,36}$ It has been shown that microglial activation correlates with neurofilament positive swellings at terminal ends of transected axons and dendrites in demyelinating lesions. In addition, the pattern of microglial targeting of neurons suggests neuronal damage via a process of synaptic stripping. ${ }^{35,37}$ Neuronal apoptosis and atrophy may result from axonal transection and other neuronal or axonal damage. In cortical gray matter lesions, there microglia are not abundant, but they are highly activated..$^{38}$ Recently, CCR2+ monocytes were found to be necessary for the development of both type 2 intracortical and type 3 subpial gray matter lesions. ${ }^{39}$

The limitations of our pilot study include its small sample size and cross-sectional design. We did not correct for multiple comparisons while assessing statistical significance, and hence, our findings represent trends that require further confirmation. Increased microglial activation has been reported in the caudate on histopathologic examination but was not detected on PET in our study, which may be due to sample size or partial volume effects diluting the PET signal in an atrophied caudate nucleus. However, this is the first study of [F-18]PBR06 PET, assessing gray matter changes in MS, demonstrating potential value of this technique. The practical advantages of this longer half-life tracer have implications for its potential clinical use in the long term, and hence, larger studies with longitudinal design are needed to confirm and extend the findings of our pilot study.

This study suggests that [F-18]PBR06 PET detects widespread abnormal brain microglial activation in the cerebral gray matter in MS, and increased activation in subcortical gray matter regions is associated with brain atrophy and physical disability. Further studies of [F-18]PBR06 PET in MS are warranted.

\section{Acknowledgment}

The authors gratefully acknowledge the participation of their patients and contributions of the staff of Biomedical Imaging Research Core and PET technologists in the Division of Nuclear Medicine and Molecular Imaging, Department of Radiology at Brigham and Women's Hospital.

\section{Study funding}

The authors gratefully acknowledge research grants from Nancy Davis Foundation's “Race to Erase MS” program, Ann Romney Center for Neurologic Diseases, Harvard NeuroDiscovery Center, and Water Cove Charitable Foundation for their support of this work. Funding agencies did not have any role in the performance of the research or preparation of the manuscript.

\section{Disclosure}

T. Singhal, K. O'Connor, S. Dubey, H. Pan, R. Chu, S. Hurwitz, S. Cicero, S. Tauhid, D. Silbersweig, E. Stern, and M.
Kijewski report no disclosures. M. DiCarli has received research grant from Spectrum Dynamics and consulting fees from GE and Sanofi. H.L. Weiner has received consulting fees from Biogen, Tiziana, Novartis, Merck Serono, and Teva Neurosciences and has received grant support from Merck Serono, Sanofi Genzyme, and Verily Life Sciences. R. Bakshi has received consulting fees from Bayer, Biogen, Celgene, EMD Serono, Genentech, Guerbet, Sanofi Genzyme, and Shire and research support from EMD Serono and Sanofi Genzyme. Go to Neurology.org/NN for full disclosures.

\section{Publication history}

Received by Neurology: Neuroimmunology \& Neuroinflammation November 19, 2018. Accepted in final form May 15, 2019.

\begin{tabular}{|c|c|c|c|}
\hline Name & Location & Role & Contribution \\
\hline $\begin{array}{l}\text { Tarun } \\
\text { Singhal, MD }\end{array}$ & $\begin{array}{l}\text { Brigham and } \\
\text { Women's Hospital, } \\
\text { Harvard Medical } \\
\text { School, Boston, MA, } \\
\text { USA }\end{array}$ & Author & $\begin{array}{l}\text { Designed and } \\
\text { conceptualized the } \\
\text { study; major role in } \\
\text { the acquisition of } \\
\text { data; analyzed and } \\
\text { interpreted the data; } \\
\text { drafted and revised } \\
\text { the manuscript for } \\
\text { intellectual content; } \\
\text { and provided funding }\end{array}$ \\
\hline $\begin{array}{l}\text { Kelsey } \\
\text { O'Connor, } \\
\text { BS }\end{array}$ & $\begin{array}{l}\text { Brigham and } \\
\text { Women's Hospital, } \\
\text { Harvard Medical } \\
\text { School, Boston, MA, } \\
\text { USA }\end{array}$ & Author & $\begin{array}{l}\text { Major role in the } \\
\text { acquisition of data } \\
\text { and analyzed and } \\
\text { interpreted the data }\end{array}$ \\
\hline $\begin{array}{l}\text { Shipra } \\
\text { Dubey, PhD }\end{array}$ & $\begin{array}{l}\text { Brigham and } \\
\text { Women's Hospital, } \\
\text { Harvard Medical } \\
\text { School, Boston, MA, } \\
\text { USA }\end{array}$ & Author & $\begin{array}{l}\text { Designed and } \\
\text { conceptualized the } \\
\text { study and major role } \\
\text { in the acquisition of } \\
\text { data }\end{array}$ \\
\hline $\begin{array}{l}\text { Hong Pan, } \\
\text { PhD }\end{array}$ & $\begin{array}{l}\text { Brigham and } \\
\text { Women's Hospital, } \\
\text { Harvard Medical } \\
\text { School, Boston, MA, } \\
\text { USA }\end{array}$ & Author & $\begin{array}{l}\text { Analyzed and } \\
\text { interpreted the data } \\
\text { and revised the } \\
\text { manuscript for } \\
\text { intellectual content }\end{array}$ \\
\hline $\begin{array}{l}\text { Renxin Chu, } \\
\text { PhD }\end{array}$ & $\begin{array}{l}\text { Brigham and } \\
\text { Women's Hospital, } \\
\text { Harvard Medical } \\
\text { School, Boston, MA, } \\
\text { USA }\end{array}$ & Author & $\begin{array}{l}\text { Analyzed and } \\
\text { interpreted the data }\end{array}$ \\
\hline $\begin{array}{l}\text { Shelley } \\
\text { Hurwitz, } \\
\text { PhD }\end{array}$ & $\begin{array}{l}\text { Brigham and } \\
\text { Women's Hospital, } \\
\text { Harvard Medical } \\
\text { School, Boston, MA, } \\
\text { USA }\end{array}$ & Author & $\begin{array}{l}\text { Analyzed and } \\
\text { interpreted the data } \\
\text { and revised the } \\
\text { manuscript for } \\
\text { intellectual content }\end{array}$ \\
\hline $\begin{array}{l}\text { Steven } \\
\text { Cicero, BS }\end{array}$ & $\begin{array}{l}\text { Brigham and } \\
\text { Women's Hospital, } \\
\text { Harvard Medical } \\
\text { School, Boston, MA, } \\
\text { USA }\end{array}$ & Author & $\begin{array}{l}\text { Major role in the } \\
\text { acquisition of data } \\
\text { and analyzed and } \\
\text { interpreted the data }\end{array}$ \\
\hline $\begin{array}{l}\text { Shahamat } \\
\text { Tauhid, MD }\end{array}$ & $\begin{array}{l}\text { Brigham and } \\
\text { Women's Hospital, } \\
\text { Harvard Medical } \\
\text { School, Boston, MA, } \\
\text { USA }\end{array}$ & Author & $\begin{array}{l}\text { Analyzed and } \\
\text { interpreted the data }\end{array}$ \\
\hline
\end{tabular}

Continued 
Appendix (continued)

\begin{tabular}{|c|c|c|c|}
\hline Name & Location & Role & Contribution \\
\hline $\begin{array}{l}\text { David } \\
\text { Silbersweig, } \\
\text { MD }\end{array}$ & $\begin{array}{l}\text { Brigham and } \\
\text { Women's Hospital, } \\
\text { Harvard Medical } \\
\text { School, Boston, MA, } \\
\text { USA }\end{array}$ & Author & $\begin{array}{l}\text { Analyzed and } \\
\text { interpreted the data } \\
\text { and revised the } \\
\text { manuscript for } \\
\text { intellectual content }\end{array}$ \\
\hline $\begin{array}{l}\text { Emily Stern, } \\
\text { MD }\end{array}$ & $\begin{array}{l}\text { Brigham and } \\
\text { Women's Hospital, } \\
\text { Harvard Medical } \\
\text { School, Boston, MA, } \\
\text { USA }\end{array}$ & Author & $\begin{array}{l}\text { Designed and } \\
\text { conceptualized the } \\
\text { study; analyzed and } \\
\text { interpreted the data; } \\
\text { and revised the } \\
\text { manuscript for } \\
\text { intellectual content }\end{array}$ \\
\hline $\begin{array}{l}\text { Marie } \\
\text { Kijewski, } \\
\text { DSc }\end{array}$ & $\begin{array}{l}\text { Brigham and } \\
\text { Women's Hospital, } \\
\text { Harvard Medical } \\
\text { School, Boston, MA, } \\
\text { USA }\end{array}$ & Author & $\begin{array}{l}\text { Designed and } \\
\text { conceptualized the } \\
\text { study; analyzed and } \\
\text { interpreted the data; } \\
\text { and revised the } \\
\text { manuscript for } \\
\text { intellectual content }\end{array}$ \\
\hline $\begin{array}{l}\text { Marcelo } \\
\text { DiCarli, MD }\end{array}$ & $\begin{array}{l}\text { Brigham and } \\
\text { Women's Hospital, } \\
\text { Harvard Medical } \\
\text { School, Boston, MA, } \\
\text { USA }\end{array}$ & Author & $\begin{array}{l}\text { Designed and } \\
\text { conceptualized the } \\
\text { study and revised the } \\
\text { manuscript for } \\
\text { intellectual content }\end{array}$ \\
\hline $\begin{array}{l}\text { Howard L. } \\
\text { Weiner, MD }\end{array}$ & $\begin{array}{l}\text { Brigham and } \\
\text { Women's Hospital, } \\
\text { Harvard Medical } \\
\text { School, Boston, MA, } \\
\text { USA }\end{array}$ & Author & $\begin{array}{l}\text { Designed and } \\
\text { conceptualized the } \\
\text { study; revised the } \\
\text { manuscript for } \\
\text { intellectual content; } \\
\text { and provided funding }\end{array}$ \\
\hline $\begin{array}{l}\text { Rohit } \\
\text { Bakshi, MD, } \\
\text { MA }\end{array}$ & $\begin{array}{l}\text { Brigham and } \\
\text { Women's Hospital, } \\
\text { Harvard Medical } \\
\text { School, Boston, MA, } \\
\text { USA }\end{array}$ & Author & $\begin{array}{l}\text { Designed and } \\
\text { conceptualized the } \\
\text { study; revised the } \\
\text { manuscript for } \\
\text { intellectual content; } \\
\text { and provided funding }\end{array}$ \\
\hline
\end{tabular}

\section{References}

1. Calabrese M, Magliozzi R, Ciccarelli O, Geurts JJ, Reynolds R, Martin R. Exploring the origins of grey matter damage in multiple sclerosis. Nat Rev Neurosci 2015;16:147-158.

2. Brownell B, Hughes JT. The distribution of plaques in the cerebrum in multiple sclerosis. J Neurol Neurosurg Psychiatry 1962;25:315-320.

3. Fisher E, Lee JC, Nakamura K, Rudick RA. Gray matter atrophy in multiple sclerosis: a longitudinal study. Ann Neurol 2008;64:255-265.

4. MacKenzie-Graham A, Kurth F, Itoh Y, et al. Disability-specific atlases of gray matter loss in relapsing-remitting multiple sclerosis. JAMA Neurol 2016;73:944-953.

5. Wang M, Gao M, Miller KD, Zheng QH. Synthesis of [(1)(1)C]PBR06 and [(1)(8) F]PBR06 as agents for positron emission tomographic (PET) imaging of the translocator protein (TSPO). Steroids 2011;76:1331-1340.

6. Singhal T, Weiner HL, Bakshi R. TSPO-PET imaging to assess cerebral microglial activation in multiple sclerosis. Semin Neurol 2017;37:546-557.

7. Lartey FM, Ahn GO, Shen B, et al. PET imaging of stroke-induced neuroinflammation in mice using [18F]PBR06. Mol Imaging Biol 2014;16:109-117.

8. James ML, Belichenko NP, Nguyen TV, et al. PET imaging of translocator protein (18 $\mathrm{kDa}$ ) in a mouse model of Alzheimer's disease using N-(2,5-dimethoxybenzyl)-2-18Ffluoro-N-(2-phenoxyphenyl)acetamide. J Nucl Med 2015;56:311-316.

9. Singhal T, O'Connor K, Dubey S, et al. 18F-PBR06 versus 11C-PBR28 PET for assessing white matter translocator protein binding in multiple sclerosis. Clin Nucl Med 2018;43:e289-e295.

10. Lublin FD, Reingold SC, Cohen JA, et al. Defining the clinical course of multiple sclerosis: the 2013 revisions. Neurology 2014;83:278-286.

11. Meier DS, Guttmann CRG, Tummala S, et al. Dual-sensitivity multiple sclerosis lesion and CSF segmentation for multichannel 3T brain MRI. J Neuroimaging 2018;28:36-47.
12. Kim G, Chu R, Yousuf F, et al. Sample size requirements for one-year treatment effects using deep gray matter volume from $3 \mathrm{~T} \mathrm{MRI} \mathrm{in} \mathrm{progressive} \mathrm{forms} \mathrm{of} \mathrm{multiple} \mathrm{scle-}$ rosis. Int J Neurosci 2017;127:971-980.

13. Dupuy SL, Tauhid S, Hurwitz S, Chu R, Yousuf F, Bakshi R. The effect of dimethyl fumarate on cerebral gray matter atrophy in multiple sclerosis. Neurol Ther 2016;5: 215-229.

14. Chu R, Tauhid S, Glanz BI, et al. Whole brain volume measured from 1.5T versus $3 \mathrm{~T}$ MRI in healthy subjects and patients with multiple sclerosis. J Neuroimaging 2016;26: 62-67.

15. Tzourio-Mazoyer N, Landeau B, Papathanassiou D, et al. Automated anatomical labeling of activations in SPM using a macroscopic anatomical parcellation of the MNI MRI single-subject brain. NeuroImage 2002;15:273-289.

16. Penny W, Friston K, Ashburner J, Kiebel S, Nichols T. Statistical Parametric Mapping The Analysis of Functional Brain Images. London: Elsevier Ltd; 2007.

17. Politis M, Giannetti P, Su P, et al. Increased PK11195 PET binding in the cortex of patients with MS correlates with disability. Neurology 2012;79:523-530.

18. Herranz E, Giannì C, Louapre C, et al. Neuroinflammatory component of gray matter pathology in multiple sclerosis. Ann Neurol 2016;80:776-790.

19. Vercellino $M$, Masera S, Lorenzatti $M$, et al. Demyelination, inflammation, and neurodegeneration in multiple sclerosis deep gray matter. J Neuropathol Exp Neurol 2009;68:489-502

20. Mahad DH, Trapp BD, Lassmann H. Pathological mechanisms in progressive multiple sclerosis. Lancet Neurol 2015;14:183-193.

21. Geurts JJ, Reuling IE, Vrenken $\mathrm{H}$, et al. MR spectroscopic evidence for thalamic and hippocampal, but not cortical, damage in multiple sclerosis. Magn Reson Med 2006; 55:478-483.

22. Azevedo CJ, Cen SY, Khadka S, et al. Thalamic atrophy in multiple sclerosis: a magnetic resonance imaging marker of neurodegeneration throughout disease. Ann Neurol 2018;83:223-234.

23. Neema M, Arora A, Healy BC, et al. Deep gray matter involvement on brain MRI scans is associated with clinical progression in multiple sclerosis. J Neuroimaging 2009; 19:3-8.

24. Rissanen E, Tuisku J, Rokka J, et al. In vivo detection of diffuse inflammation in secondary progressive multiple sclerosis using PET imaging and the radioligand $11 \mathrm{C}$ PK11195. J Nucl Med 2014;55:939-944.

25. Banati RB, Newcombe J, Gunn RN, et al. The peripheral benzodiazepine binding site in the brain in multiple sclerosis: quantitative in vivo imaging of microglia as a measure of disease activity. Brain 2000;123(pt 11):2321-2337.

26. Schweser F, Raffaini Duarte Martins AL, Hagemeier J, et al. Mapping of thalamic magnetic susceptibility in multiple sclerosis indicates decreasing iron with disease duration: a proposed mechanistic relationship between inflammation and oligodendrocyte vitality. Neuroimage 2018;167:438-452.

27. Geurts JJ, Bö L, Roosendaal SD, et al. Extensive hippocampal demyelination in multiple sclerosis. J Neuropathol Exp Neurol 2007;66:819-827.

28. Papadopoulos D, Dukes S, Patel R, Nicholas R, Vora A, Reynolds R. Substantial archaeocortical atrophy and neuronal loss in multiple sclerosis. Brain Pathol 2009;19: $238-253$.

29. Howell OW, Reeves CA, Nicholas R, et al. Meningeal inflammation is widespread and linked to cortical pathology in multiple sclerosis. Brain 2011;134 2755-2771.

30. Steenwijk MD, Geurts JJ, Daams M, et al. Cortical atrophy patterns in multiple sclerosis are non-random and clinically relevant. Brain 2016;139:115-126.

31. Colasanti A, Guo Q, Giannetti P, et al. Hippocampal neuroinflammation, functional connectivity, and depressive symptoms in multiple sclerosis. Biol Psychiatry 2016;80: $62-72$.

32. Rubio-Garrido P, Perez-de-Manzo F, Porrero C, Galazo MJ, Clasca F. Thalamic input to distal apical dendrites in neocortical layer 1 is massive and highly convergent. Cereb Cortex 2009;19:2380-2395

33. Kern KC, Gold SM, Lee B, et al. Thalamic-hippocampal-prefrontal disruption in relapsing-remitting multiple sclerosis. Neuroimage Clin 2015;8:440-447.

34. Chitnis T, Weiner HL. CNS inflammation and neurodegeneration. J Clin Invest 2017; 127:3577-3587.

35. Dutta R, Trapp BD. The pathology of multiple sclerosis. In: Cohen J, Rudick RA, editors. Multiple Sclerosis Therapeutics. 4th ed. Cambridge: Cambridge University Press; 2011:17.

36. Bar-Or A, Darlington PJ. The immunology of multiple sclerosis. In: Cohen J, Rudick RA, editors. Multiple Sclerosis Therapeutics. 4th ed. Cambridge: Cambridge University Press; 2011:20-34.

37. Trapp BD, Stys PK. Virtual hypoxia and chronic necrosis of demyelinated axons in multiple sclerosis. Lancet Neurol 2009;8:280-291.

38. Peterson JW, Bö L, Mörk S, Chang A, Trapp BD. Transected neurites, apoptotic neurons, and reduced inflammation in cortical multiple sclerosis lesions. Ann Neurol 2001;50:389-400

39. Lagumersindez-Denis N, Wrzos C, Mack M, et al. Differential contribution of immune effector mechanisms to cortical demyelination in multiple sclerosis. Acta Neuropathologica 2017;134:15-34. 


\title{
Neurology \\ Neuroimmunology \& Neuroinflammation
}

\author{
Gray matter microglial activation in relapsing vs progressive MS: A [F-18]PBR06-PET \\ study \\ Tarun Singhal, Kelsey O'Connor, Shipra Dubey, et al. \\ Neurol Neuroimmunol Neuroinflamm 2019;6; \\ DOI 10.1212/NXI.0000000000000587
}

This information is current as of July 1, 2019

\section{Updated Information \& \\ Services}

References

Citations

Subspecialty Collections

Permissions \& Licensing

Reprints including high resolution figures, can be found at:

http://nn.neurology.org/content/6/5/e587.full.html

This article cites 36 articles, 3 of which you can access for free at: http://nn.neurology.org/content/6/5/e587.full.html\#\#ref-list-1

This article has been cited by 3 HighWire-hosted articles: http://nn.neurology.org/content/6/5/e587.full.html\#\#otherarticles

This article, along with others on similar topics, appears in the following collection(s):

Multiple sclerosis

http://nn.neurology.org//cgi/collection/multiple_sclerosis

PET

http://nn.neurology.org//cgi/collection/pet

Information about reproducing this article in parts (figures,tables) or in its entirety can be found online at:

http://nn.neurology.org/misc/about.xhtml\#permissions

Information about ordering reprints can be found online:

http://nn.neurology.org/misc/addir.xhtml\#reprintsus

Neurol Neuroimmunol Neuroinflamm is an official journal of the American Academy of Neurology.

Published since April 2014, it is an open-access, online-only, continuous publication journal. Copyright

Copyright $\odot 2019$ The Author(s). Published by Wolters Kluwer Health, Inc. on behalf of the American

Academy of Neurology.. All rights reserved. Online ISSN: 2332-7812.

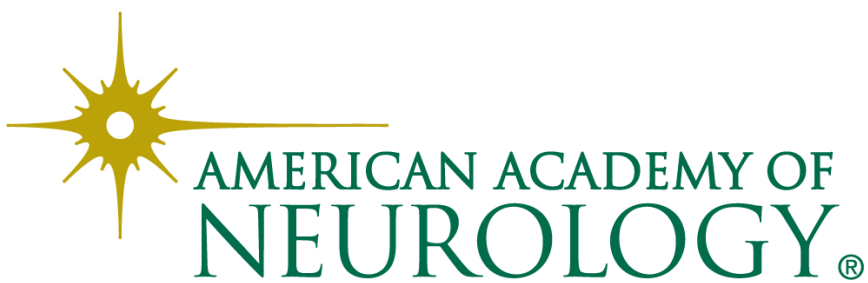

